\title{
TIPOLOGI FASAD PADA KORIDOR JALAN PEMUDA SISI SELATAN BLORA
}

\author{
Sintia Dewi Wulanningrum \\ Dosen Prodi S1 Arsitektur, Jurusan Arsitektur dan Perencanaan, Fakultas Teknik, \\ Universitas Tarumanagara, Jakarta \\ e-mail: sintiaw@ft.untar.ac.id \\ Yunita Ardianti Sabtalistia \\ Dosen Prodi S1 Arsitektur, Jurusan Arsitektur dan Perencanaan, Fakultas Teknik, \\ Universitas Tarumanagara, Jakarta \\ e-mail: yunitas@ft.untar.ac.id
}

\begin{abstract}
ABSTRAK
Jalan Pemuda merupakan jalan kolektor di Kabupaten Blora, dimana terdapat bangunan-bangunan lama yang memiliki sejarah. Pada koridor sisi selatan dipengaruhi oleh gaya arsitektur Tiongho, Belanda dan Post Modern. Fungsi bangunan terdiri dari: fungsi perdagangan dan jasa, antara lain; toko elektronik Sedar, toko bangunan, toko sembako, toko sepeda, toko sembako, toko baju, toko makanan; kantor pemerintahan; tempat ibadah, fungsi campuran dan fungsi hunian. Tujuan penelitian yaitu untuk menganalisis tipologi pada koridor sisi selatan sebanyak 21 bangunan, meliputi; tipologi atap, dinding, bukaan dan signages. Metode penelitian yang dipakai yaitu kualitatif deskriptif untuk menganalisis tipologi pada fasad bangunan sisi selatan. Hasil penelitian menunjukkan bahwa jenis atap yang berada disepanjang koridor sisi selatan antara lain ; atap pelana, atap dak beton, dan limasan; sedangkan bukaan didominasi tipe folding gate yang banyak ditemukan pada bangunan pertokoan, dan terdapat pula material kayu dan kaca pada bukaan pintu dan jendela. Pada fungsi pelayanan khusus, bangunan mendapat pengaruh dari Kebudayaan Kolonial serta pada sebagian besar fungsi hunian dan ruko mendapat pengaruh dari kebudayaan Tionghoa.
\end{abstract}

Kata kunci : Tipologi, Fasad, Jalan Pemuda

\section{ABSTRACT}

Pemuda street is a collector's road in Blora Regency, where there are old buildings that have a history. The southern side corridors are influenced by Chinese, Dutch and Post Modern architectural styles. Building functions include: trade and services functions, among others; Sedar electronics stores, building stores, grocery stores, bicycle shops, grocery stores, clothing stores, food stores; government offices; places of worship, mixed functions and residential functions. The aim of the research was to provide typology in the southern corridor of 21 buildings, including; typology of roofs, walls, openings and signages. The research method provided is qualitative descriptive to provide typological analysis in southern buildings. The results showed that the types of roofs along the corridor include; gable, flat roof, and limasan; and the openings are dominated by the folding gate type which is often found in shopping buildings, and there is also glass material in door and window openings. In the special service function, the building was influenced by the Colonial Culture and in most of the residential and shop functions were influenced by Chinese culture.

Keywords: Typology, Facade, Pemuda Street

PAWON: Jurnal Arsitektur, Nomor 01 Volume V, Januari-Juni Tahun 2021, ISSN 2597-7636 


\section{PENDAHULUAN}

Pada koridor Jalan Pemuda terdapat berbagai fungsi bangunan, seperti; fungsi perdagangan dan jasa, fungsi perkantoran (Kantor Pemerintahan maupun Kantor Swasta), fungsi peruntukkan khusus (Satuan Lalu Lintas Blora, Kodim Blora, Markas Militer); fungsi pelayanan khusus (Gereja Santo Pius x, Kelenteng Hok Tik Bio), fungsi campuran (rumah toko) dan fungsi hunian. Gaya arsitektur yang berbeda-beda pada koridor Jalan Pemuda sisi selatan, dapat dilihat dari fasad bangunannya. Fasad menyampaikan keadaan budaya saat bangunan dibangun, fasad mengungkapkan kriteria tatanan dan penataan, dan berfungsi memberikan kemungkinan dan kreativitas dalam ornamen dan dekorasi (Utami,2013). Tipologi arsitektur memiliki keterkaitan dengan penelusuran elemen-elemen yang membentuk arsitektural. Elemen arsitektur tersebut dapat digunakan untuk mengidentifikasi tipologi dari suatu bangunan dengan mengklasifikasi kesamaan bentuk, struktur, dan karakter dari bangunan (Keling,2016). Tipologi fasad pada bangunan disepanjang koridor Jalan Pemuda sisi selatan, dapat dilihat melaui bagian atap, bukaan, pintu serta ornamen yang mendapat pengaruh dari arsitektur Cina, Belanda dan Post Modern.

Berdasarkan fenomena diatas, rumusan masalah pada penelitian yaitu: bagaimana tipologi pada fasad bangunan yang meliputi atap, dinding, bukaan dan bagaimana pengaruh langgam terhadap tipologi bangunan.

Tujuan penulisan artikel yaitu untuk menganalisis tipologi (atap, dinding, bukaan, signages) pada koridor Jalan Pemuda sisi selatan, serta mengidentifikasi pengaruh kebudayaan yang terdapat di sepanjang koridor sisi selatan.

\section{TINJAUAN PUSTAKA}

Tipologi bangunan adalah sebuah studi atau penyelidikan tentang penggabungan elemen-elemen yang memungkinkan untuk mencapai/ mendapatkan klasifikasi organisme arsitektur melalui tipe-tipe (Vilder dalam Damayanti,2017).

Menurut Krier (1996), fasad adalah elemen dalam arsitektur yang dapat mengekspresikan fungsi dan maksud sebuah bangunan. Fasad bangunan komersial berfungsi sebagai elemen fisik bangunan dan identitas terkait fungsi komersialnya. Menurut Triady (2012) tipologi merupakan suatu metode pengelompokan beberapa tipe atau jenis suatu objek berdasarkan karakternya.Menurut Lippsmeier (1980) elemen fasad dari sebuah bangunan yang sekaligus merupakan komponenkomponen yang mempengaruhi fasad bangunan antara lain: atap; dinding; lantai.

Di dalam buku Ching (2000), dalam memahami sebuah bentuk terlebih dahulu harus memahami unsur-unsur visual bentuk antara lain : wujud, dimensi; warna; tekstur. Menurut Sumalyo (1995) dalam Wulur (2015), kebudayaan Belanda tidak saja memengaruhi kehidupan masyarakat Indonesia saja, tetapi juga, cara berpikir para arsitek Belanda, ketika menerapkan konsep-konsep lokal atau tradisional pada bangunan-bangunan rancangannya. Arsitektur Kolonial di Indonesia adalah fenomena budaya yang unik (percampuran budaya antara penjajah dan budaya Indonesia), dan tidak terdapat di lain tempat, termasuk negara-negara bekas koloni lainnya (Sumalyo,1995). Keunikan bangunanbangunan tersebut dapat dilihat pada bentuk-bentuk bangunan peninggalan Kolonial Belanda.

Orang-orang Tionghoa yang ada di Indonesia sekarang, dulunya sebagian besar berasal dari propinsi-propinsi Tiongkok Selatan (Guangdong dan Fujian).

PAWON: Jurnal Arsitektur, Nomor 01 Volume V, Januari-Juni Tahun 2020, ISSN 2597-7636 
Kebanyakan mereka ini berasal dari kalangan pekerja (buruh, petani, nelayan dan sebagainya), sehingga arsitektur yang dibawanya menunjukkan tradisi kerakyatan (Hadinoto,2008). Perwujudan bangunan arsitektur Tionghoa yaitu: Kelenteng; Ruko (rumah toko); serta rumah tinggal.

Post Modern bila diartikan secara harfiah kata-katanya terdiri atas 'Post' yang artinya masa sesudah dan 'Modern' yang artinya era modern maka dapat disimpulkan bahwa Post Modern adalah masa sesudah era Modern (era diatas tahun 1960 an).Post Modernism sendiri merupakan suatu aliran baru yang menentang segala sesuatu kesempurnaan dari modernism, bahkan tak jarang menentang aturan yang ada dan mencampurkan berbagai macam gaya (Mokoginta,2016).

\section{METODE PENELITIAN}

Metode penelitian yang digunakan yaitu kualitatif deskriptif. Kualitatif deskriptif digunakan untuk menganalisis tipologi fasad di koridor Jalan Pemuda. Metode pengumpulan data diperoleh melalui data primer dan data sekunder. Data primer diperoleh melalui survey lapangan, observasi di di koridor Jalan Pemuda,Blora. Data sekunder diperoleh melalui kajian literatur seperti; jurnal dan buku yang berkaitan tentang tipologi fasad. Grounded research digunakan untuk merumuskan fenomena-fenomena yang ada di sepanjang koridor bangunan yang yang diteliti sebanyak 21 sampel bangunan.

\section{HASIL DAN PEMBAHASAN}

Pada koridor sisi selatan Jalan Pemuda, Blora didominasi oleh fungsi perdagangan dan jasa antara lain; toko elektronik Sedar, toko bangunan (Wesi Aji, Tiga Utama) toko sembako, toko sepeda (Enggal Jaya), toko sembako (Toko Prima), toko baju, toko pulsa, toko makanan (Quick Chicken), kantor pemerintahan (Kantor Bupati Kabupaten Blora, Kantor Dinas Sosial, Kantor Perumda BPR, Kantor Penanaman Modal), tempat ibadah (Kelenteng Hok Tik Bio, Gereja Katolik Santo Pius X), toko Honda, toko Suzuki toko Viar, Poltas Blora, Polisi Militer Blora, Kodim Blora, ruko, fungsi hunian.

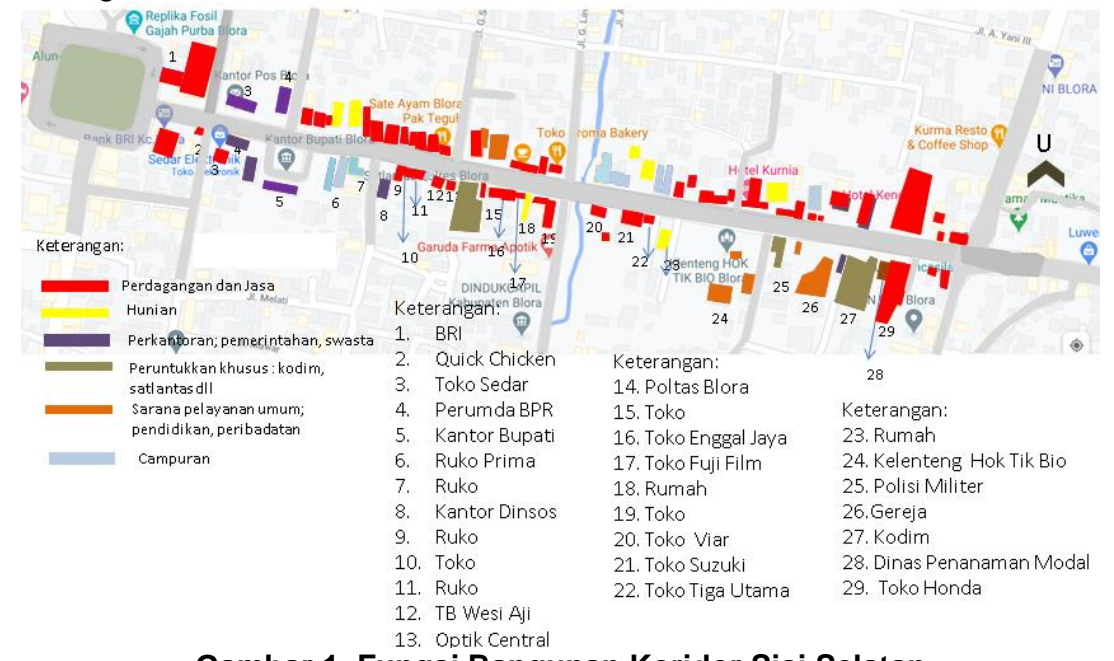

Gambar 1. Fungsi Bangunan Koridor Sisi Selatan

Sumber : Penulis,2020

PAWON: Jurnal Arsitektur, Nomor 01 Volume V, Januari-Juni Tahun 2021, ISSN 2597-7636 


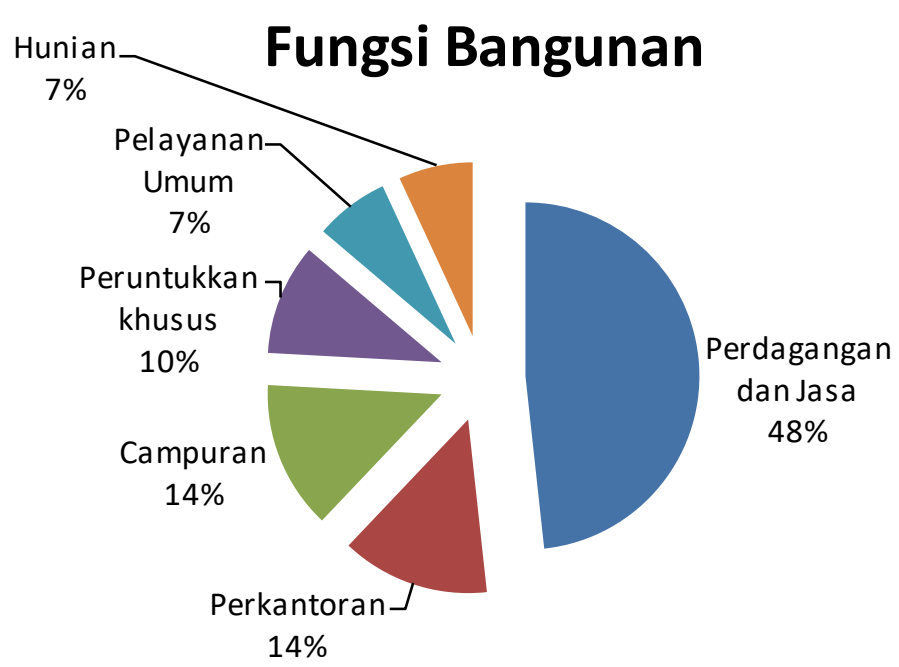

Gambar 2. Persentase Fungsi Bangunan

Sumber : Penulis,2020

Berdasarkan hasil survey, sebagain besar fungsi bangunan yang berada disepanjang koridor Jalan Pemuda sisi selatan yaitu sebagai fungsi perdagangan dan jasa sebanyak 48\% (toko elektronik Sedar, toko bangunan (Wesi Aji, Tiga Utama) toko sembako, toko sepeda (Enggal Jaya), toko sembako (Toko Prima), toko baju, toko pulsa, toko makanan (Quick Chicken); sebagai fungsi perkantoran sebanyak 14\% (Kantor Bupati Kabupaten Blora, Kantor Dinas Sosial, Kantor Dinas Penanaman Modal); fungsi campuran sebanyak 14\% (rumah dan toko); peruntukkan khusus sebanyak 10\% (Kodim, Markas Polisi Militer dan Satlantas Blora); pelayanan umum sebanyak 7\% (Gereja Katolik Santo Pius X, Klenteng Hok Tik Bio); sebagai fungsi hunian sebanyak $7 \%$.

Tabel 1. Tipologi Bangunan di Koridor Jalan Pemuda Sisi Selatan

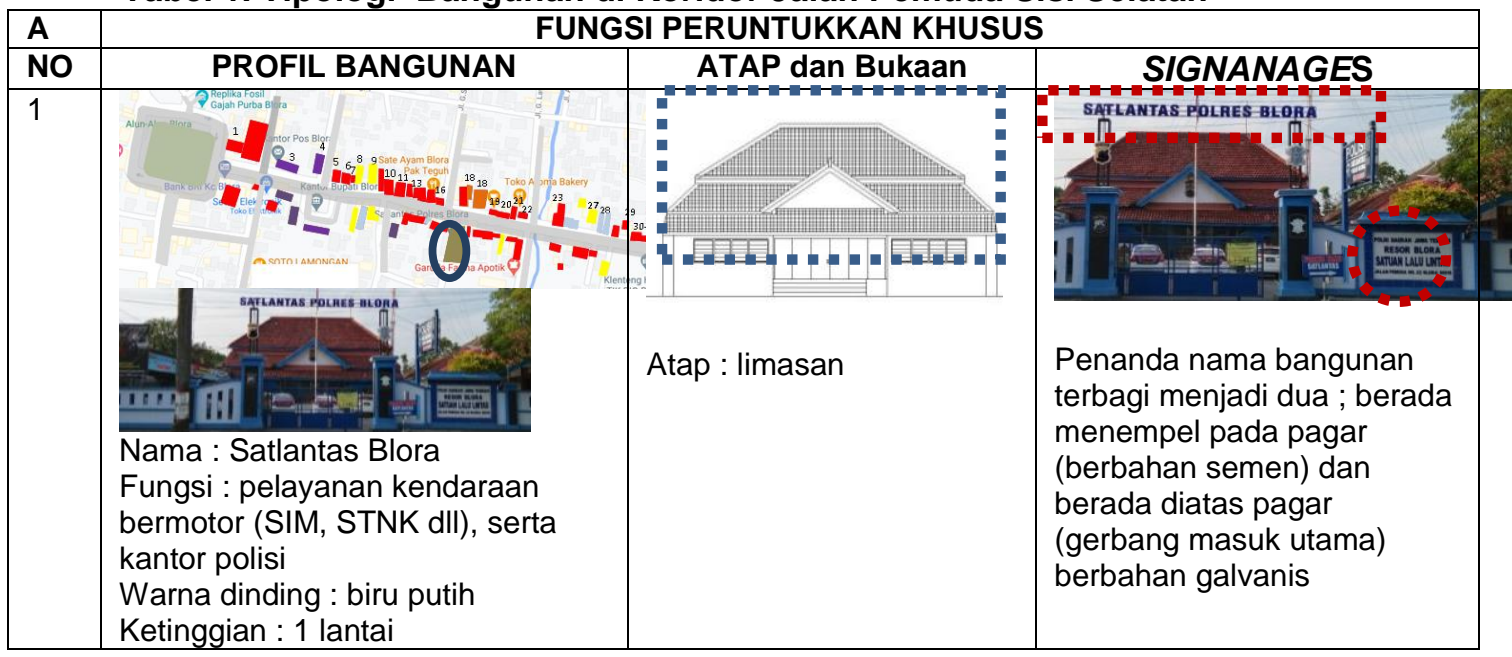

PAWON: Jurnal Arsitektur, Nomor 01 Volume V, Januari-Juni Tahun 2020, ISSN 2597-7636 


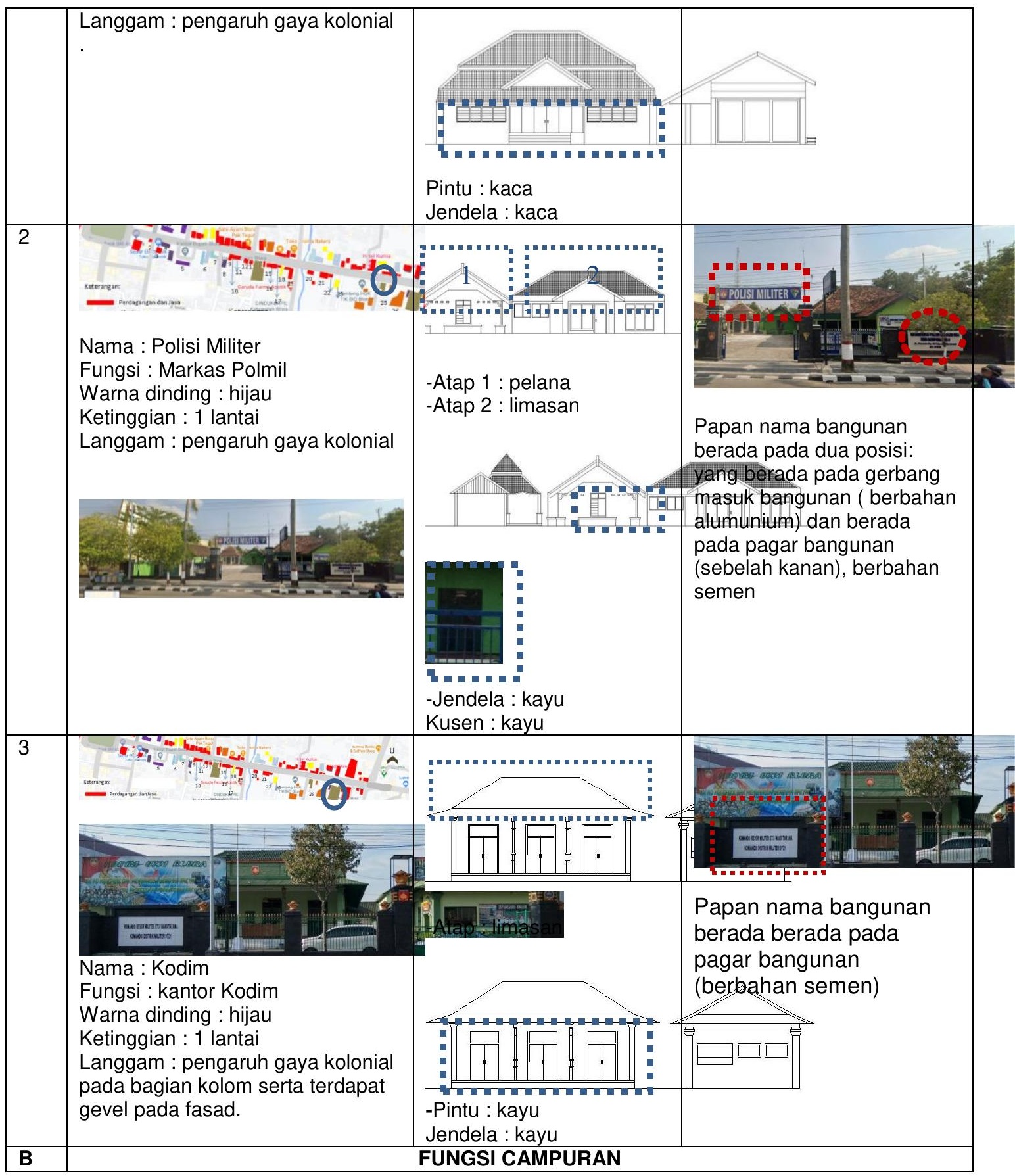

PAWON: Jurnal Arsitektur, Nomor 01 Volume V, Januari-Juni Tahun 2021, ISSN 2597-7636 


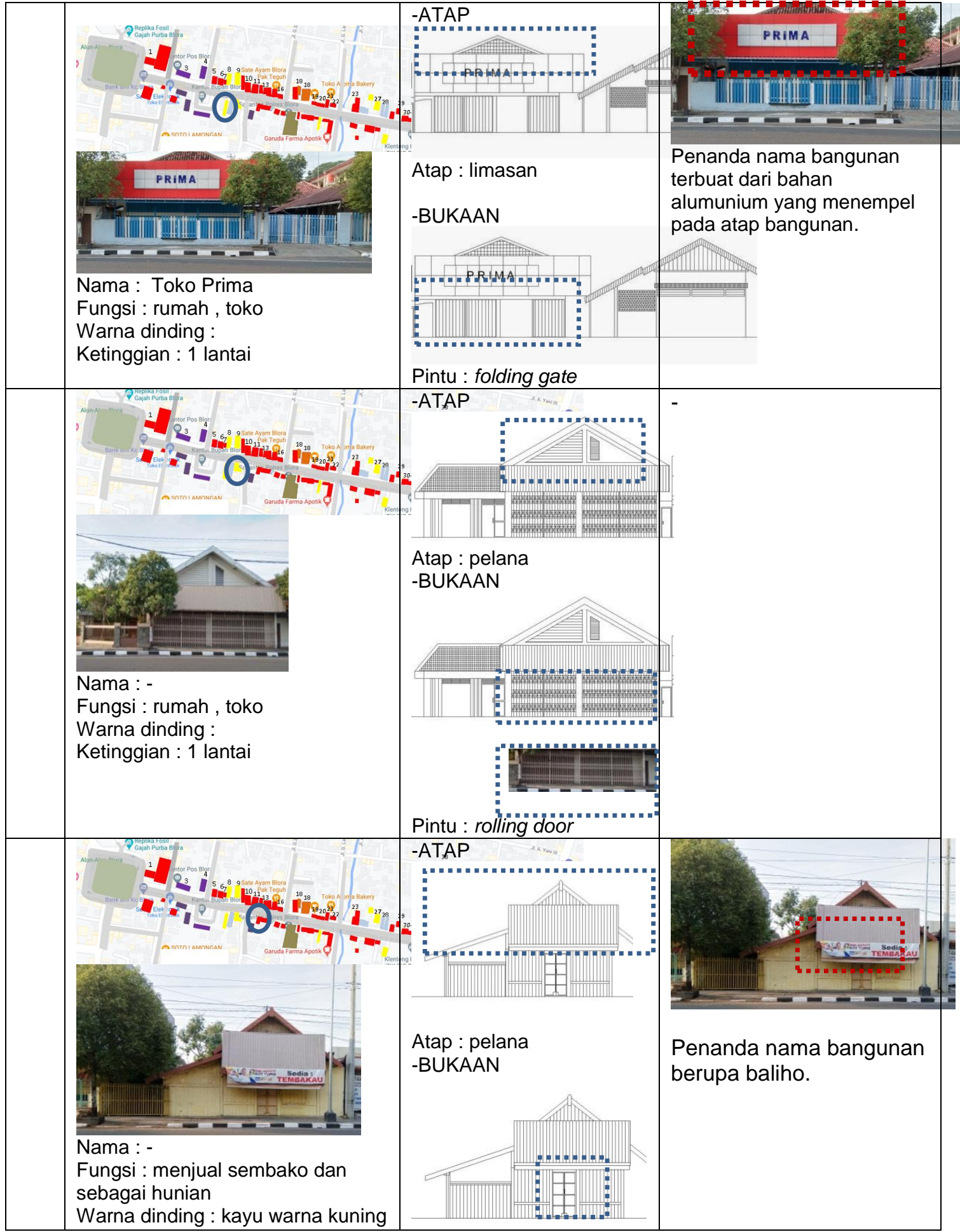

PAWON: Jurnal Arsitektur, Nomor 01 Volume V, Januari-Juni Tahun 2020, ISSN 2597-7636 


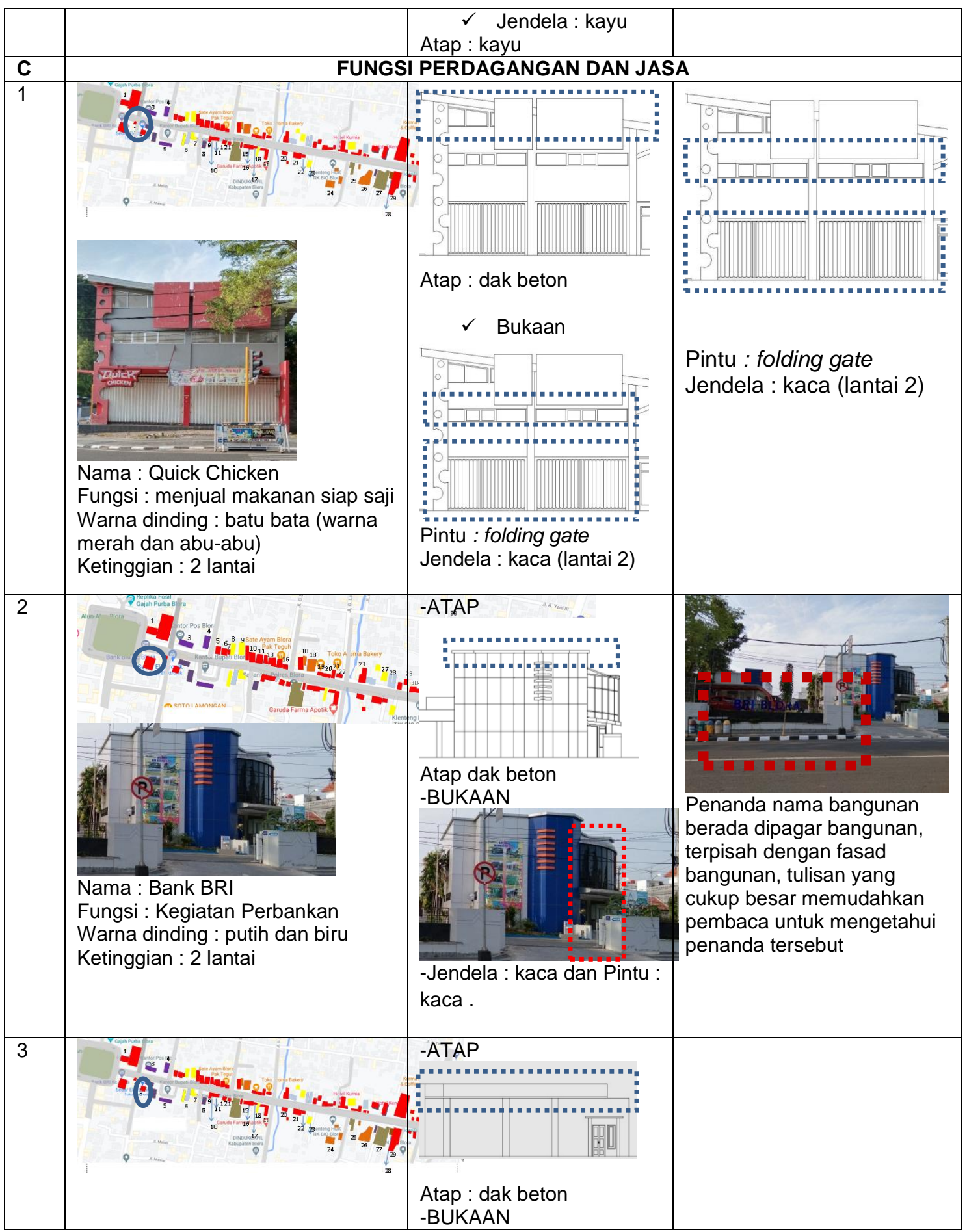

PAWON: Jurnal Arsitektur, Nomor 01 Volume V, Januari-Juni Tahun 2021, ISSN 2597-7636 


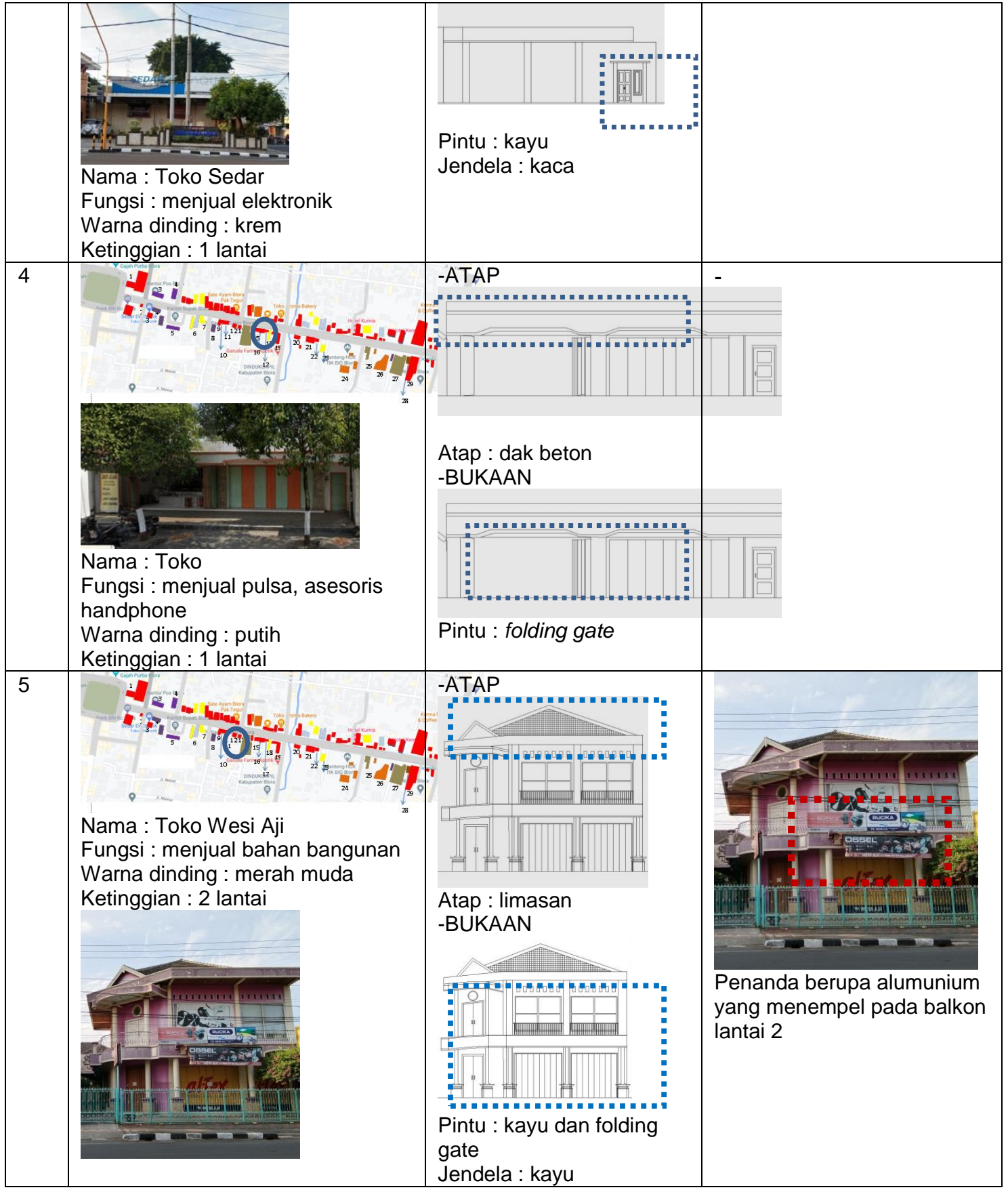

PAWON: Jurnal Arsitektur, Nomor 01 Volume V, Januari-Juni Tahun 2020, ISSN 2597-7636 


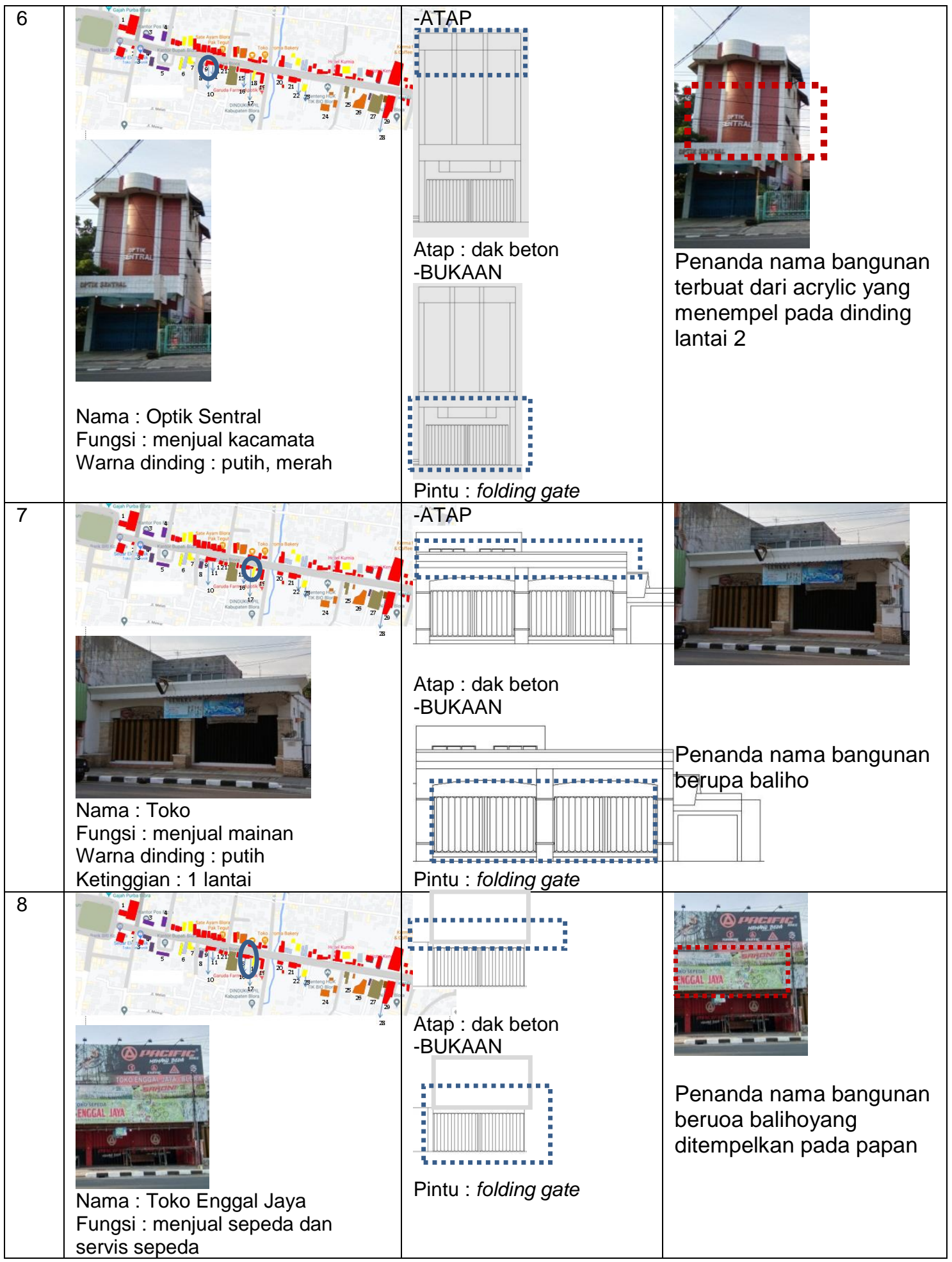

PAWON: Jurnal Arsitektur, Nomor 01 Volume V, Januari-Juni Tahun 2021, ISSN 2597-7636 


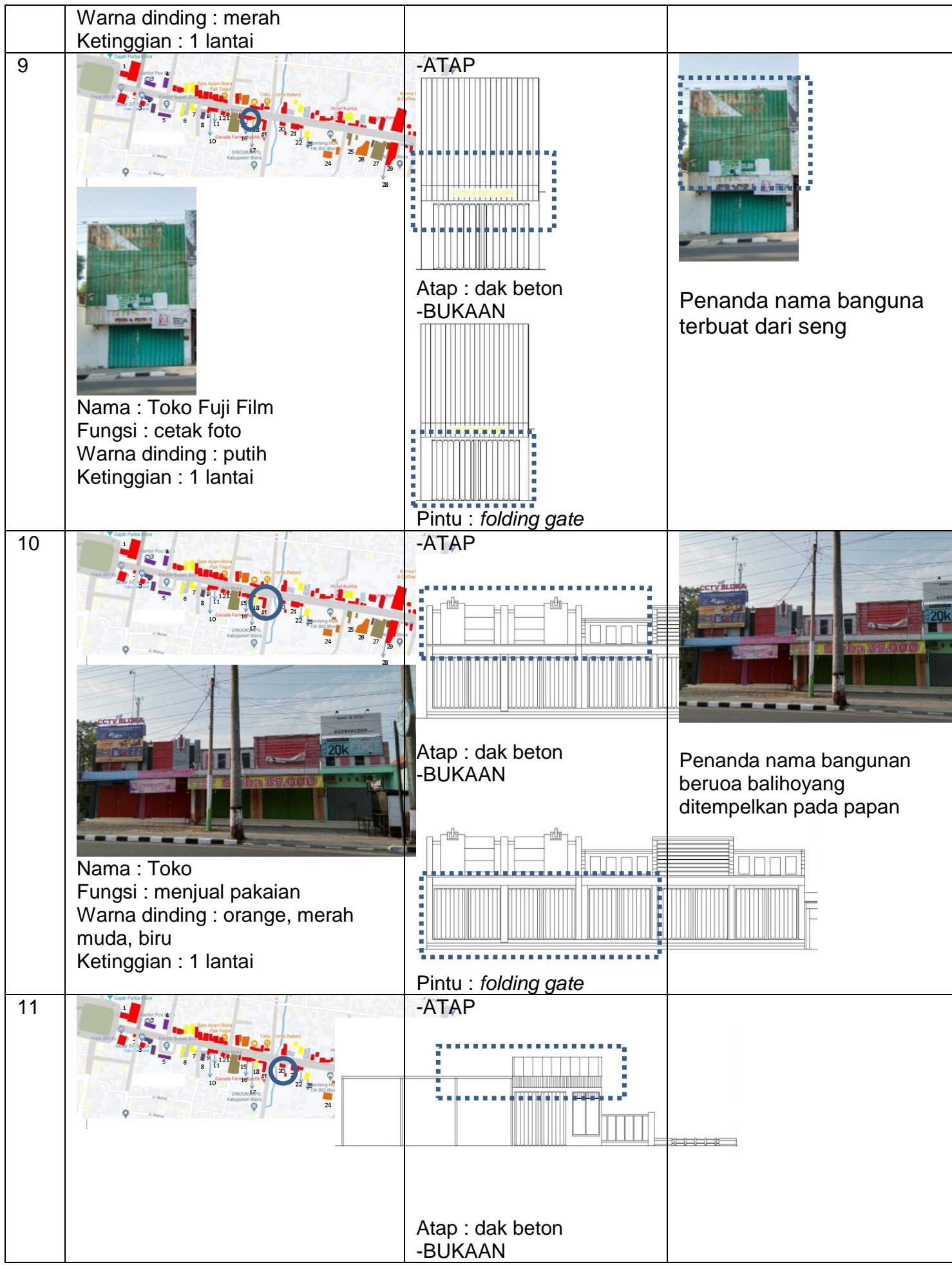

PAWON: Jurnal Arsitektur, Nomor 01 Volume V, Januari-Juni Tahun 2020, ISSN 2597-7636 


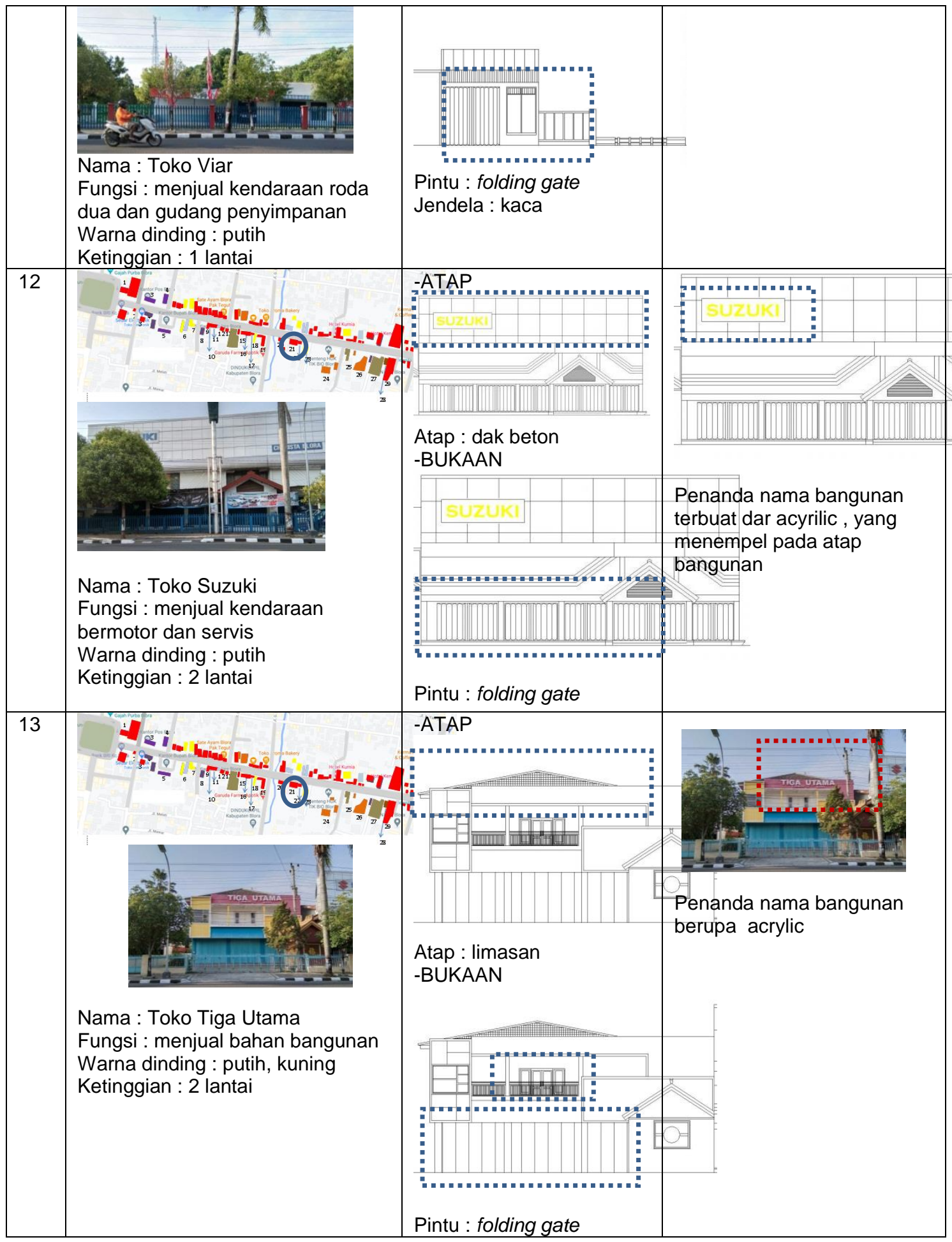

PAWON: Jurnal Arsitektur, Nomor 01 Volume V, Januari-Juni Tahun 2021, ISSN 2597-7636 


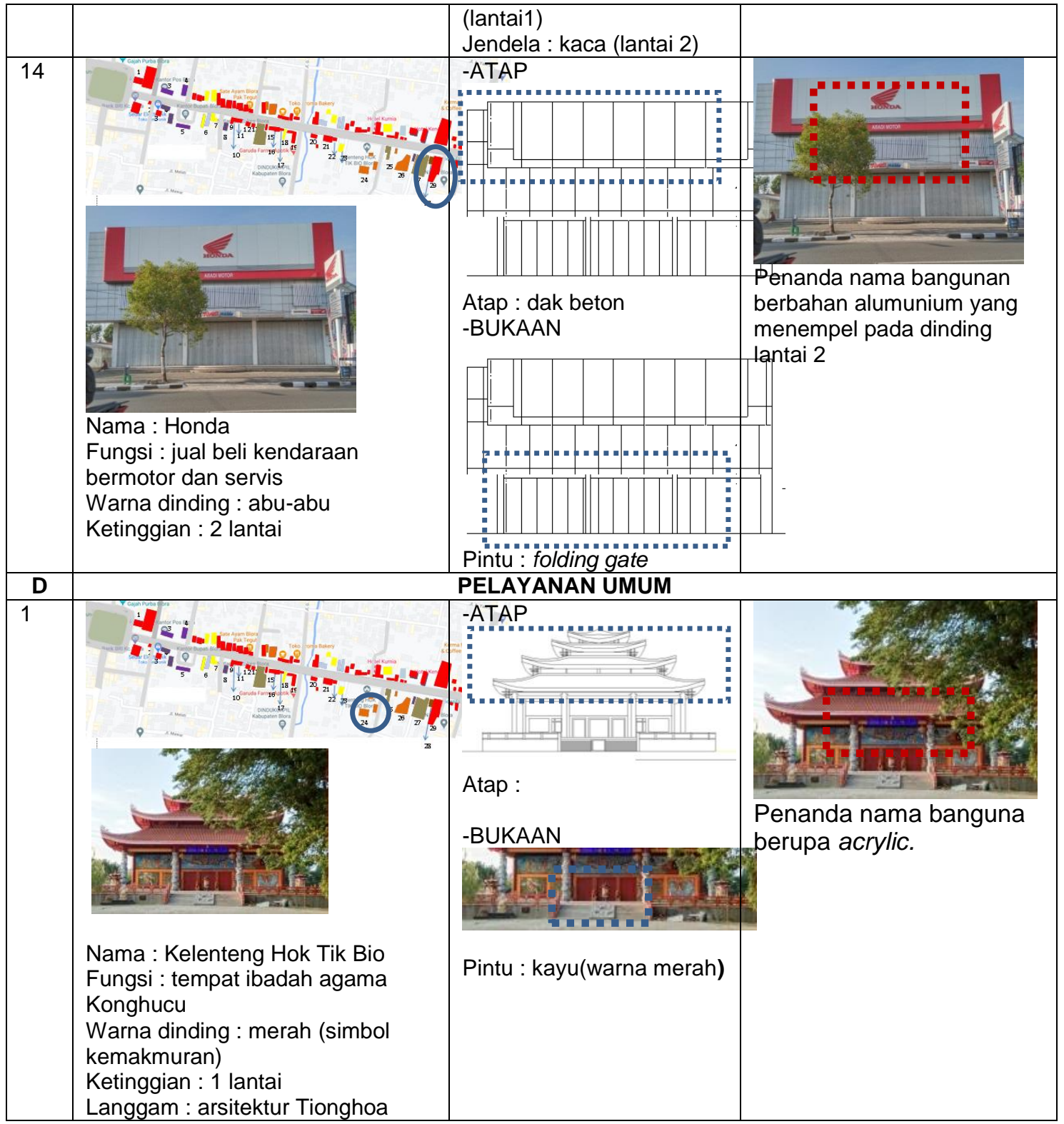

PAWON: Jurnal Arsitektur, Nomor 01 Volume V, Januari-Juni Tahun 2020, ISSN 2597-7636 


\begin{tabular}{|c|c|c|c|}
\hline 2 & $\begin{array}{l}\text { Nama : Gereja Santo Pius } \mathrm{x} \\
\text { Fungsi : tempat ibadah agama } \\
\text { Warna dinding : orange } \\
\text { Ketinggian : 1 lantai }\end{array}$ & $\begin{array}{l}\text { Atap : dak beton miring } \\
\text { (mengikuti konsep } \\
\text { bangunan yang berbentuk } \\
\text { kapal) } \\
\text {-BUKAAN } \\
\text { Bukaan (jendela vertikal) } \\
\text { pada bagian fasad, } \\
\text { material kaca }\end{array}$ & ${ }^{2}$ \\
\hline $\mathrm{E}$ & & UNGSI PERKANTORAN & \\
\hline 1 & $\begin{array}{l}\text { Nama : kantor PERUMDA BPR } \\
\text { Fungsi : perkantoran } \\
\text { Warna dinding : orange, putih } \\
\text { Ketinggian : 2 lantai }\end{array}$ & 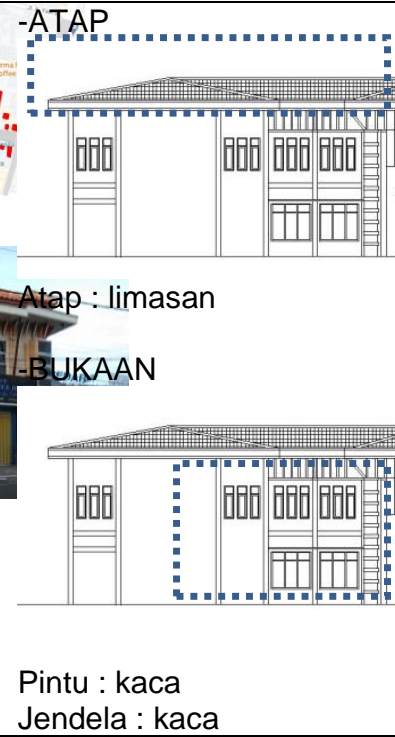 & 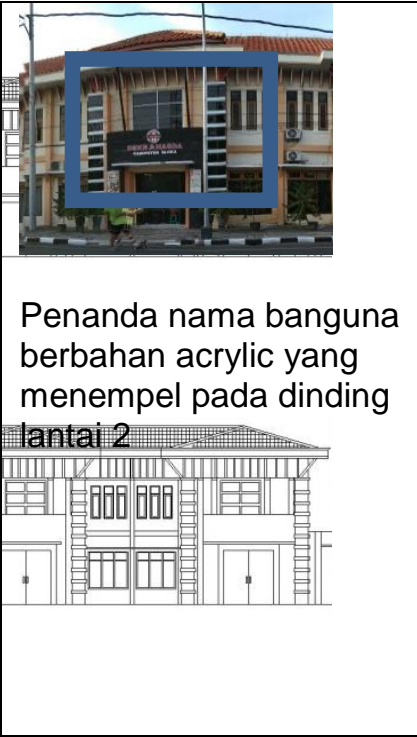 \\
\hline
\end{tabular}

PAWON: Jurnal Arsitektur, Nomor 01 Volume V, Januari-Juni Tahun 2021, ISSN 2597-7636 


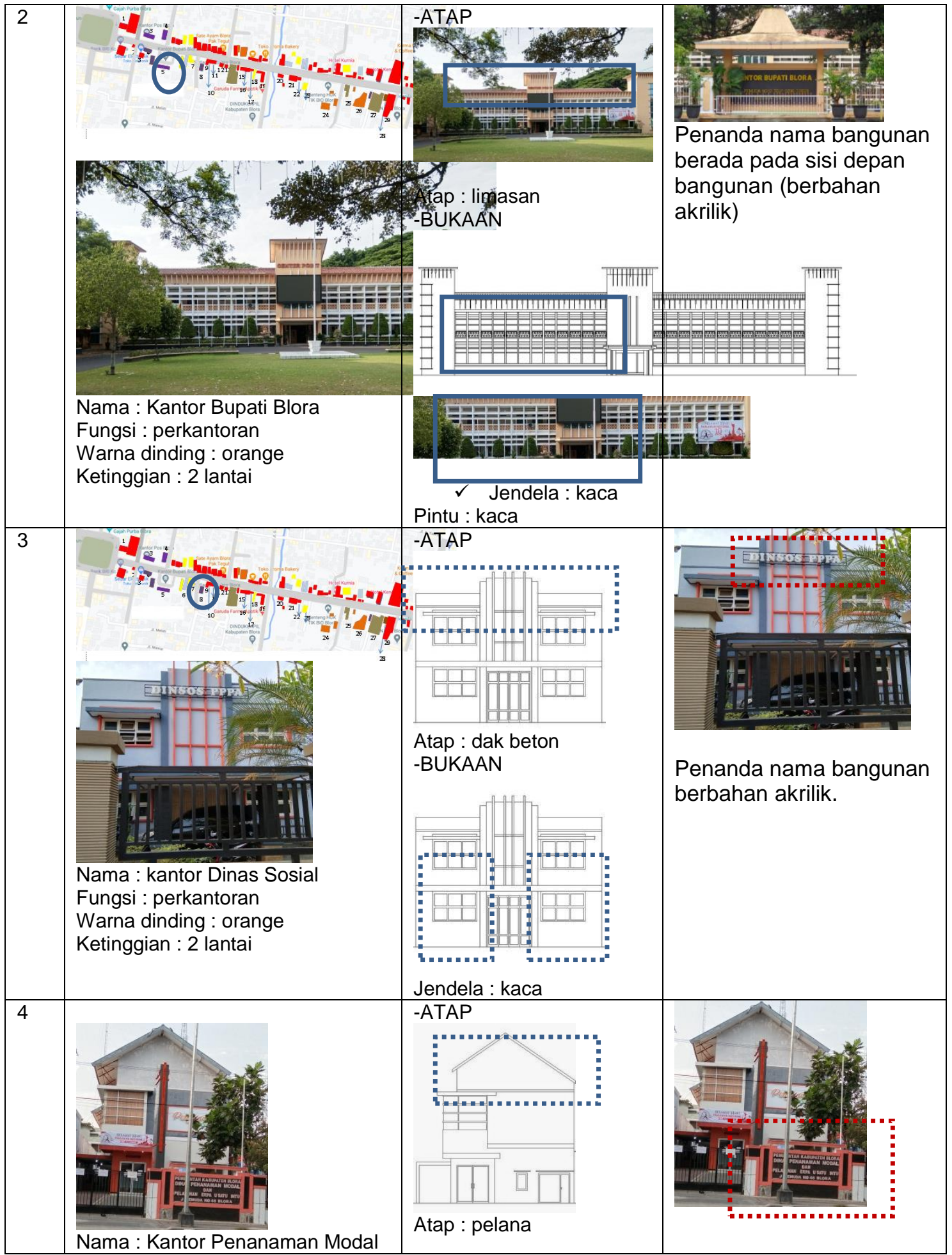

PAWON: Jurnal Arsitektur, Nomor 01 Volume V, Januari-Juni Tahun 2020, ISSN 2597-7636 


\begin{tabular}{|c|c|c|c|}
\hline & $\begin{array}{l}\text { Fungsi : perkantoran } \\
\text { Warna dinding : putih } \\
\text { Ketinggian : } 2 \text { lantai }\end{array}$ & $\begin{array}{l}\text {-BUKAAN } \\
\text { Pintu: kace } \\
\text { Jendela : }\end{array}$ & $\begin{array}{l}\text { Penanda nama bangunan } \\
\text { menempel pada pagar } \\
\text { bangunan }\end{array}$ \\
\hline$F$ & \multicolumn{3}{|c|}{ FUNGSI HUNIAN } \\
\hline & $\begin{array}{l}\text { Nama : - } \\
\text { Wangsi : hunian } \\
\text { Keting dinding : putih : 1 lantai }\end{array}$ & -Atap : pela & - \\
\hline
\end{tabular}

Sumber : Penulis, 2020

Fungsi bangunan yang berada disepanjang koridor Jalan Pemuda sisi selatan antara lain; fungsi perdagangan dan jasa, seperti: toko elektronik Sedar, toko bangunan (Wesi Aji, Tiga Utama) toko sembako, toko sepeda (Enggal Jaya), toko sembako (Toko Prima), toko baju, toko pulsa, toko makanan (Quick Chicken) sebanyak $48 \%$ didominasi pengaruh gaya Post-Modern; fungsi perkantoran (Kantor Bupati Kabupaten Blora, Kantor Dinas Sosial, Kantor Dinas Penanaman Modal) sebanyak $14 \%$ didominasi gaya Post-Modern; fungsi campuran sebanyak $14 \%$ (rumah dan toko) mendapat pengaruh kebudayaan Tionghoa; serta peruntukkan khusus sebanyak 10\% (Kodim, Markas Polisi Militer dan Satlantas Blora) mendapat pengaruh kebudayaan Kolonial; pelayanan umum sebanyak 7\% (Gereja Katolik Santo Pius X, Klenteng Hok Tik Bio) mendapat pengaruh gaya arsitektur PostModern (Gereja Santo Pius) dan kebudayaan Tionghoa (Kelenteng Hok Tik Bio); sebagai fungsi hunian sebanyak $7 \%$ mendapat pengaruh dari kebudayaan Tionghoa.

Tipologi gaya bangunan didominasi dengan gaya arsitektur Post-Modern, serta terdapat juga pengaruh dari gaya arsitektur Cina dan gaya arsitektur Kolonial. Pada arsitektur Post-Modern tipologi atap berupa atap dak beton, bukaan berupa jendela kaca, pintu kaca,serta folding gate, signanes berupa papan nama berbahan akrilik. Pada gaya bangunan Tionghoa, tipologi atap berupa atap limasan dan pelana, bukaan berupa folding gate pada ruko dan jendela kayu dan kaca pada rumah tinggal, signanes pada ruko berupa akrilik dan baliho nama toko. Sedangkan tipologi pada bangunan Kolonial memiliki atap berupa atap limasan, bukaan didominasi 
pintu dan jendela kayu, terdapat pula jendela kaca, signanes pada bangunan berbahan akrilik. Fungsi bangunan yaitu sebagai pelayanan khusus antara lain: Satlantas Blora, Kodim, Polisi Militer.

\section{KESIMPULAN}

Pada koridor Jalan Pemuda pada sisi selatan memiliki berbagai jenis fungsi bangunan seperti : fungsi perdagangan dan jasa, fungsi perkantoran, pelayanan umum, pelayanan khusus, campuran dan fungsi hunian. Pada tipologi bentuk atap didomiasi oleh bentuk atap dak beton, limasan dan pelana. Pada bukaan sebagian besar memiliki tipe pintu folding gate terutama pada fungsi perdagangan dan jasa, sedangkan pada jendela berbahan kaca dan kayu, sedangkan untuk signages pada fungsi perdagangan dan jasa didominasi bahan akrilik, sedangkan untuk ruko berupa baliho. Gaya arsitektur pada koridor sisi selatan didominasi oleh gaya arsitektur Post-modern , gaya arsitektur Cina, serta Kolonial.

\section{Saran}

Diperlukan penelitian lanjutan terkait koridor sisi utara, serta upaya dari pemerintah untuk mempertahankan bangunan lama yang berada di sepanjang koridor sisi selatan, karena beberapa bangunan sudah diganti dengan gaya bangunan modern, sehingga nilai-nilai sejarah pada bangunan lama tergantikan dengan bangunan baru yang tidak memiliki nilai histroris, serta perlu adanya regulasi terkait bangunan lama, supaya dapat dijaga dan dipertahankan.

\section{DAFTAR PUSTAKA}

Ching, D. (2000). Arsitektur, bentuk, ruang, dan Tatanan edisi II. Jakarta: Erlangga. Damayanti1,Fifi., Nugroho ,A.M., Santosa,Herry. (2017). Tipologi Rumah Jawa Di Kawasan Perdesaan Sumber Polaman Lawang . Jurnal Reka Buana Volume 2 No 1.

Handinoto. (2008). "Perkembangan Bangunan Etnis Tionghoa di Indonesia (Akhir Abad ke 19 sampai tahun 1960 an).

Keling, Gendro. (2016). Tipologi Bangunan Kolonial Belanda di Singaraja. Forum Arkeologi, Vol. 29, No. 2..

Krier, Rob. (1996).Komposisi Arsitektur, diterjemahkan oleh : Ir. Effendi Setiadarma, 1988, Jakarta : Erlangga

Lippsmeier, G. (1980). Bangunan Tropis (Edisi ke-2). Jakarta: Erlangga

Mokoginta ,Ferry,. Sondakh, Julianus A.R. (2016). Penerapan Konsep Arsitektur Post Modern Pada Pengembangan Bangunan Universitas Dumoga Di Kotamobagu. Jurnal Arsitektur DASENG UNSRAT,Vol.5 No.2.

Rukmana, C.D., Santoso, H., et all,. (2017). Tipologi fasade bangunan komersial di kawasan koridor jalan Soekarno-Hatta Malang. Jurnal Mahasiswa Jurusan Arsitektur, Vol. 5, No. 1.

Utami, Firmansyah,I.A., Haerani.P.A., et al. (2013). Kajian Bentuk Dan Fasade Hotel Hilton Bandung. Jurnal Rekayasa, Vol.1 No.1

Triady, A. Y. 2012. Tipologi Regol/Pagar Rumah Tradisional di Laweyan Surakarta Wulur,F.A., Kumurur,V.A., Kaunang,I.R.B. (2015).Gaya bangunan arsitektur kolonial pada bangunan umum Bersejarah di Kota Manado. Jurnal Sabua,Vol.7 N0.1. 